\title{
Great Data, Nice Tale, but What's the Message? The OHIM/EPO Study on the Economic Relevance of IP-Intensive Industries in the EU
}

\author{
Annette Kur - Dietmar Harhoff
}

(C) Max Planck Institute for Innovation and Competition, Munich 2014

In September 2013, a Report on the Contribution of Intellectual Property (IP) Intensive Industries to Economic Performance and Employment in the EU ("the Report") was launched by the Office for Harmonisation in the Internal Market (OHIM) and the European Patent Office (EPO). ${ }^{1}$ The study was performed in fulfillment of the mandate assigned to the European Observatory on Infringements of Intellectual Property Rights (Observatory) to provide evidence-based data on the impact, role and public perception of intellectual property in the EU. It stands in close correspondence to the analogous study undertaken by the Patent Office of the USA (USPTO) that was published in March 2012. As main findings of the Report, it is highlighted that IP-intensive industries contribute $26 \%$ of employment and $39 \%$ of GDP in the EU - figures that are proudly presented as "impressive" in a foreword accompanying the study (p. 3).

There is no doubt that the Report reflects a high level of professional skill in regards to methodology and data interpretation. Not unexpectedly, most data confirm what could be assumed; their virtue lies in adding reliable figures to what are otherwise mere conjectures. For instance, whereas it is not a novel insight that the manufacture of communication equipment is particularly patent-prone, the report establishes that the number of patents per employee in the "manufacture of powerdriven hand tools" (109.74) exceeds the average number of patents per employee in

\footnotetext{
1 Available at http://ec.europa.eu/internal_market/intellectual-property/docs/joint-report-epo-ohim-finalversion_en.pdf.
}

\footnotetext{
A. Kur $(\bowtie)$

Professor Dr.; Senior Researcher and Head of Unit

Max Planck Institute for Innovation and Competition, Munich, Germany

e-mail: annette.kur@ip.mpg.de

D. Harhoff

Professor, Ph.D.; Director

Max Planck Institute for Innovation and Competition, Munich, Germany

e-mail: dietmar.harhoff@ip.mpg.de
} 
all industry sectors (0.69) approximately by the factor 150. In none of the other IP sectors is the discrepancy between average and top sector IP intensity as stark as here. It is also interesting, though not entirely surprising, that the Report shows similar results as the one conducted in the USA (with some deviances that might in part be explained by the fact that the USPTO study did not include industrial designs), and that the bulk of IP activities relates to the secondary sector (manufacturing), whereas services are less prominently involved. The country comparisons in chapter 6 reveal interesting patterns of industrial specialization within the EU economy, and possibly the report as a whole should best be understood as an illuminating description of country differences in industry composition.

What the Report cannot provide, however, is evidence regarding the causal relationship between IP and the economic data. It cannot reveal whether (or to what degree) IP protection is a factor which as such boosts the economic performance of certain industries or countries. The researchers conducting the study, mostly economists, were prudent enough to make that disclaimer in their own foreword (p. 18). However, the reservation is neither contained in the executive summary, nor does it find an echo in public statements by representatives of EPO and OHIM citing the Report. The executive summary rather emphasizes that while the Report itself does not make policy recommendations, it "is designed to provide evidence that can be used by policymakers in their work, and to serve as basis for raising awareness of Intellectual Property among Europe's citizens" (p. 5; emphasis added). This triggers the question as to what exactly the evidence used by policymakers should be. What, for instance, can be inferred from the fact that IP-intensive industries - defined as industries in which the ratio of IP rights per 1000 employees lies above the aggregated average account for $26 \%$ of employment in the EU? Concluding that those jobs are generated because of the industries being IP-intensive would be as (il)logical as concluding, from the fact that it is the non-IP-intensive sector which after all accounts for the remaining $74 \%$ of all jobs, that IP tends to be a job-killer. Similarly, the fact that the GDP and employment shares in industries using geographical indications intensively are on the order of 0.2 and $0.1 \%$ (p. 80) does not constitute evidence that these IPRs are largely irrelevant. However, in spite of the inconclusiveness of the findings regarding causal relationships, IP-prone publications such the World IP Review (WIPR), trumpet loudly that "[i]t's official: IP boosts the economy". ${ }^{2}$

Indeed, the temptation is obvious to employ the data established in the Report for political purposes, most notably for initiatives strengthening IP rights further and bolstering the protection against IP infringement. ${ }^{3}$ To be sure, hardly anybody would contend that $26 \%$ of all jobs in the EU and $39 \%$ of the GDP are in jeopardy unless rigorous measures are taken to safeguard the interests of IP proprietors; ${ }^{4}$ it is

\footnotetext{
${ }^{2}$ WIPR, 1 June 2014, at http://www.worldipreview.com/article/it-s-official-ip-boosts-the-economy (headline of the article presenting findings of the Report).

${ }^{3}$ For an actual example see Communication from the Commission to the European Parliament, the Council and the European Economic and Social Committee, Towards a renewed consensus on the enforcement of Intellectual Property Rights: An EU Action Plan (COM/2014/0392 final).

${ }^{4}$ In the WIPR article (supra note 2), Paul Maier, the director of the Observatory, explicitly warns against such unfounded statements. However, it is to be feared that such voices of prudence are drowned out by the surrounding noise of those who want to exploit the study for political purposes.
} 
far too obvious that such statements cannot be sustained. However, the emphasis placed in official communiqués on the "impressive figures" resulting from the Report conveys a subtext subtly pointing in exactly that direction.

Whether or not that hidden message reaches its goal will likely depend on the addressees. Regarding consumers, hopes that the data may assist in raising awareness for the importance of IP might be in vain. Until now the public in the EU has proven relatively immune to all sorts of similar campaigns, and showcasing economic data relating to IP-intensive industries might not change much. The young, tech-savvy consumers that the campaign would need to reach in order to turn the widespread indifference vis-à-vis IP protection ${ }^{5}$ into a positive attitude are notoriously skeptical, and they may be sophisticated enough to realize that the figures presented by the Report are moot in regards of causal effects, be it on the economy in general or on specific sectors. Indeed, regarding the effects of filesharing and other forms of (mostly illegal) downloading, the study offers much less information and specialized research than what was provided by previous investigations of the music market, most of which arrived at the (certainly not uncontestable) conclusion that the overall economic damage inflicted by such practices is rather modest, if traceable at all. ${ }^{6}$

On the political level, however, the strategy might prove more successful, given that policymakers are regularly quite susceptible to arguments invoking the dangers of piracy and counterfeiting. For instance, the European Parliament and the majority of the Council recently backed the proposal made by the Commission in the trademark reform package that goods in transit, whether or not they are meant for diversion on the European market, are considered as infringing if they bear, without authorization of the right holder, a trademark that is identical or quasi-identical with an EU mark. Behind that move apparently lies the oft-provoked fear that if full respect were paid to established principles of territoriality and freedom of international trade, the EU market would be flooded with counterfeit goods threatening the health and security of EU citizens. ${ }^{7}$ In such a climate, the Report could easily be (mis)used for adding an element of economic seriousness to the usual well-worn anti-piracy rhetoric, with little concern for the plausibility of the argument.

\footnotetext{
5 See "European Citizens and Intellectual Property: Perception, Awareness and Behaviour"; a study undertaken and published by the Observatory together with the Report on the economic performance of IP-intensive industries; available at https://oami.europa.eu/ohimportal/en/web/observatory/ip_perception.

6 "Ups and downs - Economische en culturele gevolgen van file sharing voor muziek, film en games", http://www.tno.nl/content.cfm?context=thema\&content=inno_publicatie\&laag1=897\&laag2=918\&item_ $\mathrm{id}=473$ ), the same result is endorsed in a study conducted on the same topic by the Swiss government, http://www.ejpd.admin.ch/content/ejpd/de/home/dokumentation/mi/2011/2011-11-30.html).

7 European Parliament legislative resolution of 25 February 2014 (COM(2013)0162 - C7-0088/2013 2013/0089(COD)) - on the TMD - and (COM(2013)0161 - C7-0087/2013 - 2013/0088(COD)) - on the CTMR, at http://www.europarl.europa.eu/sides/getDoc.do?type=TA\&language=EN\&reference=P7-TA2014-0118, amendments 55 and 56, respectively. For the Council decision see Presidency compromise proposal of 2 May 2014, PI 53 CODEC 1190 (TMD); PI 52 CODEC 1188 (CTMR); at register.consilium.europa.eu/pdf/en/14/st09/st09558.en14.pdf. The arguments for endorsing the Commission proposal are refuted in a non-paper by representatives of the UK, Belgium, Hungary, the Czech Republic, Austria, and Denmark (on file with the author).
} 
Attempts of that kind are certainly not in the best interest of those who conducted the research summarized in the Report. Actually, such attempts might discredit the analytical results and the advances in setting up a comprehensive database of IP rights utilization at the firm level. The researchers' work deserves being evaluated for what it is - a compilation of data diligently arranged and computed, resulting in findings that are interesting as such. But these results do not lend themselves to normative extrapolations of any kind. Instead of insinuating anything like that, the representatives of the institutions involved would be well advised to be as candid about that as the research team itself.

As policymakers are nowadays under great pressure to base legislation on economic evidence, they are badly in need of resilient data explaining and supporting their decisions. Hence, empirical analysis is highly welcome where it fends off irrational policy choices that have lost contact with the reality of the market. However, such analyses may become detrimental where the relevance of data is misinterpreted and overrated.

What is needed, therefore, is a more realistic appraisal of what the specific contribution of empirical studies to the understanding of IP is. Causal evidence on the effect of IP rights is still rare, and it tends to address specific and sometimes narrow areas of IP rights use. But given the attention that is now accorded to the issues, better evidence may be at hand in the near future. Regarding the OHIM/EPO Report, it should simply be acknowledged that it is a tale without a message - at least none that conveys relevant insights about the economic effects of IP as such. 